
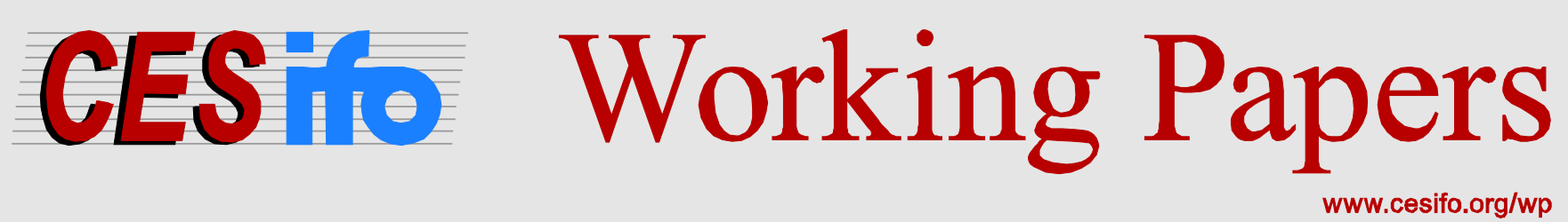

\title{
Monetary Policy Transparency
}

\author{
Petra M. Geraats
}

\author{
CESIFO WORKING PAPER NO. 4611 \\ CATEGory 7: MONETARY POLICY AND INTERNATIONAL FinANCE \\ JANUARY 2014
}
An electronic version of the paper may be downloaded
- from the SSRN website:
- from the RePEc website:
- from the CESifo website:
wWw.SSRN.com
Www.RePEc.org
www.CESifo-group.org/wp

\section{CESifo}




\title{
Monetary Policy Transparency
}

\begin{abstract}
There has been a remarkable rise in the transparency of monetary policy during the last two decades. This paper provides an overview of the ways in which central banks have been providing more information about their monetary policymaking. Furthermore, it reviews the theoretical literature on monetary policy transparency and relevant empirical findings. The focus is on understanding two key developments, the notable increase in openness about macroeconomic prospects and the recent advance of forward policy guidance.
\end{abstract}

JEL-Code: E520, E580.

Keywords: monetary policy, transparency, central banks.

\author{
Petra M. Geraats \\ Faculty of Economics \\ University of Cambridge \\ UK - Cambridge, CB3 9DD \\ Petra.Geraats@econ.cam.ac.uk
}

December 2013

This paper has been prepared for the Handbook of Economic and Institutional Transparency. I thank Philippe Gugler, Michael Plummer, Dick Sweeney and other participants of the Handbook workshops in Trolleholm and Mölle for helpful comments, and Barry Eichengreen and Nergiz Dincer for sharing their extensive transparency data set. 


\section{Introduction}

Monetary policymaking has undergone a dramatic transformation during the last 25 years. Central banks used to be known for their secrecy, leaving people to guess their intentions. But nowadays most central banks announce their objectives with quantitative targets and publish numerical macroeconomic forecasts. They have also become much more open about their policy decisions and several even give explicit guidance about upcoming policy moves. Transparency has become a key feature of monetary policymaking and central banks consider it very important. ${ }^{1}$ This is partly because many central banks have become independent, which has been accompanied by formal accountability requirements. But foremost, central banks have adopted transparency to make monetary policy more effective.

This rise in monetary policy transparency has happened in two phases. The first wave towards greater openness occurred during the 1990s, when central banks became more explicit about their monetary policy objectives and started to publish their analysis of macroeconomic developments and prospects in regular monetary policy reports. This was most notable for central banks that adopted inflation targeting as their monetary policy strategy. The Bank of England was a leading example in terms of such macroeconomic transparency. The second wave towards greater disclosure happened during the 2000s, when transparency became more widespread and a vanguard of central banks pursued further openness through forward guidance on their policy settings. A prominent example of the latter is the Swedish Riksbank.

This paper provides an overview of the various ways in which central banks throughout the world have become more transparent about their monetary policymaking. It uses the conceptual framework of Geraats (2002) to distinguish several aspects of transparency and two types of effects of information disclosure. The main focus of the paper is a review of theory and evidence related to the two most notable ways in which monetary policy has become more transparent. First, the publication of macroeconomic forecasts and analysis, which has made it easier

\footnotetext{
${ }^{1}$ In a survey of 94 central banks by Fry, Julius, Mahadeva, Roger and Sterne (2000), 74\% of central banks considered transparency a 'vital' or 'very important' component of their monetary policy framework. Blinder (2000) finds in a survey of 88 central bankers that they consider transparency a very important factor to establish or maintain credibility.
} 
for the public to infer the central bank's intentions from its monetary policy actions and outcomes, thereby allowing greater accountability. Second, the current frontier in monetary policy transparency, the disclosure of forward guidance about policy actions. This allows the private sector to align their expectations with those of the central bank, which enhances the effectiveness of monetary policy. In both cases, central bank communications provide an important policy tool to influence private sector expectations and improve macroeconomic outcomes.

There are several other surveys on monetary policy transparency that cover theory, practice and empirical evidence to various extents. Geraats (2002), Hahn (2002) and Carpenter (2004) focus on the (early) theoretical literature. Geraats (2006, 2009) documents information disclosure practices and trends throughout the world. Blinder, Ehrmann, Fratzscher, De Haan and Jansen (2008) concentrate on the empirical literature on the financial market effects of central bank communications, whereas Van Der Cruijsen and Eijffinger (2010) provide an overview of many theoretical and empirical contributions on the macroeconomic effects of monetary policy transparency. The present paper provides an up-to-date overview of transparency practices and trends. In addition, from the large literature on monetary policy transparency it distills the main theoretical arguments and empirical evidence that are relevant to understanding the key developments.

The remainder of this paper is organized as follows. Section 2 presents a conceptual framework for transparency. Empirical measures, practices and trends in monetary policy transparency are reviewed in section 3. Theory and evidence regarding macroeconomic transparency are covered in section 4 , while forward guidance about policy settings is extensively discussed in section 5. To conclude, section 6 summarizes the main insights.

\section{Conceptual Framework}

An economic definition of transparency is the absence of asymmetric information. Thus, monetary policy transparency refers to the extent to which information relevant to monetary policymaking is publicly known. In the case of perfect transparency, all agents are equally well-informed.

Complete openness by disclosing all data, documents and meeting transcripts is not sufficient for transparency, however, in the presence of frictions in infor- 
mation processing. So central banks use carefully crafted communications (such as policy announcements and monetary policy reports) to transmit relevant information and achieve greater transparency. But these communications may not be received or correctly understood by everyone due to frictions in information transmission. ${ }^{2}$ As a result, perfect transparency is an ideal that is practically impossible to obtain, though it is still a useful benchmark.

From a theoretical point of view, there is a powerful argument in favor of transparency. According to the first fundamental welfare theorem, in a world with asymmetric information but no other market imperfections, moving to perfect transparency is welfare improving as it leads to the first-best outcome. In the real world, however, there are many market imperfections, so an increase in transparency may not be beneficial. The effects are likely to depend on the particular circumstances and the specific information that is disclosed. Nevertheless, there are generally two types of effects of transparency (Geraats 2002), which could be labeled information and incentive effects.

Information effects are the ex post consequences of disclosing a particular piece of information. These could be beneficial, such as a reduction in uncertainty. But there could also be negative repercussions as economic agents update their expectations in response to the information, which could lead to higher economic volatility.

Incentive effects are the ex ante structural changes in economic behavior due to the different information structure. For instance, a central bank that is going to publish its macroeconomic forecasts is likely to put greater effort in its forecasting, which results in better monetary policymaking. But the private sector may focus too much on the published forecasts and underweight its own signals.

Morris and Shin (2002) have presented an influential theoretical argument against transparency based on a negative incentive effect. Assuming economic agents have a motive to coordinate their actions, they put disproportionate weight on public information compared to their private signals. So, public disclosure of relatively noisy information (e.g. early estimates of statistics or unreliable forecasts) could induce undue economic volatility. In addition, the stronger reliance on public communications has the negative side-effect that it reduces the infor-

\footnotetext{
${ }^{2}$ For a discussion of transparency in terms of openness, clarity and common understanding, see Winkler (2002).
} 


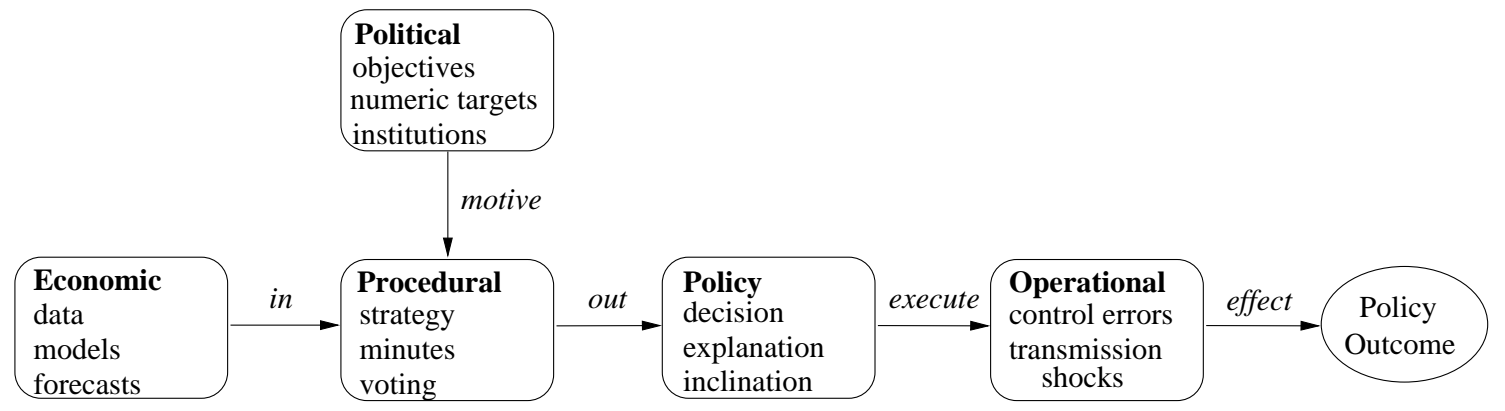

Figure 1: Conceptual framework for transparency aspects.

mativeness of market expectations (Morris and Shin 2005). Furthermore, public disclosures could crowd out private sector efforts to acquire information and thereby potentially worsen private sector forecasts (Tong 2007, Kool, Middeldorp and Rosenkranz 2011). This provides a cautionary tale that transparency need not be beneficial, especially if the disclosed information is noisy.

The effects of transparency are also likely to depend on what kind of information is released, so it is useful to discern several aspects of transparency. Geraats (2002) distinguishes five aspects relevant to policymaking: political, economic, procedural, policy and operational transparency, which are illustrated in Figure 1.

Political transparency refers to clarity about the policy objectives and institutional framework (for example through an explicit inflation target and central bank independence). Economic transparency focuses on the economic information used for the policy decision (such as macroeconomic forecasts and policy models). Procedural transparency provides openness about the way policy decisions are taken (by publishing a monetary policy strategy, minutes and voting records of policy meetings). Policy transparency involves the communication of the policy stance (including the policy decision, policy explanations and inclinations with respect to future policy actions). Operational transparency concerns the implementation of the policy actions (such as control errors in operating instruments and disturbances in policy transmission).

Clearly, transparency is a multi-faceted concept, which has sparked a rich theoretical literature, but also complicated empirical measurement. 


\section{Transparency Measures and Trends}

This section first discusses empirical measures of monetary policy transparency. This is followed by a review of current information disclosure practices and trends for central banks throughout the world.

\subsection{Empirical Measures}

Central banks differ considerably in the extent to which they are transparent in various respects. Researchers have tried to measure this in several ways.

One approach is to assess public understanding of monetary policymaking. Van Der Cruijsen, Jansen and De Haan (2010) used the DNB Household Survey in the Netherlands to test how well the Dutch public understands the monetary policy objectives of the European Central Bank (ECB), which revealed considerable ignorance and misunderstanding, indicating limited (political) transparency. Although such a survey has the potential to directly detect imperfect information about monetary policymaking, it would be cumbersome to consistently measure monetary policy transparency across countries in this way.

Another approach is to evaluate publicly available information relevant to monetary policymaking, which would indicate the degree of monetary policy transparency in the absence of frictions in information transmission and processing. One could assess the quality of central bank publications, like Fracasso, Genberg and Wyplosz (2003) who graded the inflation reports of 20 inflation targeters and ranked the United Kingdom, New Zealand and Brazil highest in terms of transparency. But it is more common to examine whether particular types of information pertinent to monetary policymaking are publicly available.

There are a several transparency measures based on information disclosure practices. Fry et al. (2000) provide a valuable dataset using a survey of 94 central banks conducted in 1998. They assigned top marks to Norway, Sweden and the United Kingdom for forward-looking analysis (mostly economic transparency), while Japan and the United States scored highest on explaining policy decisions (procedural and policy transparency). Overall, their measure of monetary policy explanations rated Sweden and the United States as the most transparent, closely followed by the United Kingdom and then New Zealand. 
Eijffinger and Geraats (2006) construct a systematic index of monetary policy transparency that distinguishes political, economic, procedural, policy and operational transparency. Their dataset documents information disclosures for 9 major central banks from 1998 to 2002, revealing a rise in transparency. According to their index, the United Kingdom was the most transparent in 1998, closely followed by Canada and New Zealand, but by 2002 it had been overtaken by both New Zealand and Sweden.

Crowe and Meade (2008) present an alternative transparency index that also captures political, economic, procedural, policy and operational aspects. They used the Fry et al. (2000) dataset from 1998, supplemented by data collected for 37 central banks in 2006, and found a significant increase in economic and policy transparency for advanced economies.

The most extensive dataset on monetary policy transparency is by Dincer and Eichengreen (2013), who compiled the Eijffinger-Geraats index for 120 central banks from 1998 to 2010. They find that the increase in central bank disclosure has not been confined to advanced economies, which are on average the most transparent, with Sweden and New Zealand ranking highest in 2010; developing countries and most notably emerging markets have also become much more transparent, though the latter less so since 2007. All in all, there has been a substantial rise in monetary policy transparency throughout the world.

\subsection{Practices and Trends}

Following Geraats (2009), the Dincer and Eichengreen (2013) dataset can be used to further analyze information disclosure practices and trends. Table 1 shows to what extent various types of information relevant to monetary policymaking were disclosed in 1998, 2004 and 2010, listed by transparency aspect.

Regarding political transparency, although a formal statement of monetary policy objectives is nearly universal, less than half of central banks provide an explicit prioritization or primary objective. Quantification of objectives has expanded from less than one-half of central banks in 1998 to two-thirds in 2010, most prominently in the form of an explicit inflation target, which was pioneered by New Zealand in 1989. Explicit instrument independence has spread from around one-third to one-half of central banks, but this may understate de facto 
Table 1: Trends in monetary policy transparency

\begin{tabular}{|c|c|c|c|c|}
\hline Frequency of information disclosure (in percent) & 1998 & 2004 & 2010 & Change \\
\hline \multicolumn{5}{|l|}{ Political transparency } \\
\hline - Monetary policy objectives & 90.8 & 95.0 & 96.6 & 5.8 \\
\hline with prioritization & 36.7 & 45.8 & 46.6 & 9.9 \\
\hline - Quantified objective & 44.2 & 60.8 & 66.4 & 22.2 \\
\hline - Explicit instrument independence & 34.2 & 49.2 & 53.4 & 19.2 \\
\hline \multicolumn{5}{|l|}{ Economic transparency } \\
\hline - Numerical macroeconomic forecasts & 14.2 & 46.7 & 54.3 & 40.1 \\
\hline quarterly, medium term for inflation and output & 3.3 & 11.7 & 19.8 & 16.5 \\
\hline - Macroeconomic policy model & 5.0 & 15.0 & 24.1 & 19.1 \\
\hline \multicolumn{5}{|l|}{ Procedural transparency } \\
\hline - Monetary policy strategy & 50.0 & 65.0 & 73.3 & 23.3 \\
\hline - Minutes & 5.0 & 9.2 & 16.4 & 11.4 \\
\hline - Voting records & 4.2 & 6.7 & 10.3 & 6.1 \\
\hline \multicolumn{5}{|l|}{ Policy transparency } \\
\hline - Policy adjustment & 15.0 & 40.0 & 46.6 & 31.6 \\
\hline - Policy explanation & 12.5 & 32.5 & 43.1 & 30.6 \\
\hline - Policy inclination & 0.0 & 2.5 & 4.3 & 4.3 \\
\hline \multicolumn{5}{|l|}{ Operational transparency } \\
\hline - Control errors operating target & 9.2 & 20.8 & 22.4 & 13.2 \\
\hline - Transmission disturbances & 15.8 & 42.5 & 47.4 & 31.6 \\
\hline - Evaluation monetary policy outcomes & 33.3 & 61.7 & 61.2 & 27.9 \\
\hline Sample size & 120 & 120 & 116 & \\
\hline
\end{tabular}

Notes: Information disclosure deduced from Eijffinger-Geraats transparency index scores in Dincer and Eichengreen (2013) data set. Change from 1998 to 2010 in percent point. Sample size declined as Cyprus, Malta, Slovakia and Slovenia joined euro area.

independence as a large majority of central banks in the Fry et al. (2000) survey reported enjoying independence without significant qualifications. Although independence generally entails disclosure requirements to ensure accountability, central banks tend to be much more transparent than formally required. 
According to the Fry et al. (2000) survey about two-thirds of central banks regularly published forward-looking analysis in 1998, but often only qualitative assessments. The Dincer and Eichengreen (2013) dataset reveals a remarkable improvement in economic transparency involving quantitative information. The publication of numerical macroeconomic forecasts greatly expanded from $14 \%$ of central banks in 1998 to $54 \%$ in 2010. Although initially few central banks released their medium-term forecasts for both inflation and output at quarterly frequency, this rose to one-fifth of central banks in 2010. The publication of the macroeconomic policy model used by the central bank jumped to nearly a quarter of central banks. The Bank of England has been a leading example in economic transparency, especially the colorful 'fan charts' it introduced in the mid 1990s to show its projected path for inflation and output growth, with confidence bands illustrating the underlying uncertainty.

Concerning procedural transparency, the use of an explicit monetary policy strategy (such as inflation targeting) increased from a half to nearly three quarters of central banks. But revealing information about monetary policy deliberations through the timely publication of minutes (which are generally non-verbatim and non-attributed) or voting records (whether individual or non-attributed) is much less common, although it has significantly increased. In this respect, a very high degree of openness is provided by the Swedish Riksbank, which promptly reveals individual voting records through attributed reservations in the policy announcements, and publishes minutes of its policy meetings after two weeks, with a detailed, attributed account of the discussion (since mid 2007).

Policy transparency in the form of a prompt announcement and explanation of policy adjustments, has greatly expanded from around $15 \%$ to $45 \%$ of central banks, although it is less common to provide an explanation when policy settings remain unchanged (which frequently happens as the monetary policy instrument is usually only adjusted in discrete steps, like 25 basis points for policy rates). Some central banks also provide forward guidance indicating the likely direction, timing or pace of upcoming policy moves. For example, the US Federal Reserve has often signaled its policy inclination since 1999, initially using code words and phrases in its policy statements, such as the 'balance of risks' toward 'heightened inflation pressures' or 'economic weakness' (from 2000 to early 2003), maintaining 'policy accommodation' for a 'considerable period' and subsequently remov- 
ing it at a 'measured' pace (from mid 2003 to 2005), and keeping the policy rate near zero for an 'extended period' (from early 2009 to mid 2011). The Federal Reserve turned to more detailed, quantitative forward guidance about the timing of tightening policy in mid 2011, first by specifying a calendar date, and then (in late 2012) by setting a threshold for the unemployment rate. Furthermore, it has published its projected policy path since early 2012 .

There have also been notable increases in operational transparency. Openness about control errors in the operating target (which could be sizeable, especially for monetary aggregates) has increased from less than one-tenth to over one-fifth of central banks. Information about unanticipated disturbances affecting monetary policy transmission, often through an analysis of short-term macroeconomic developments in monetary policy reports, has expanded from around $15 \%$ to $45 \%$ of central banks. A review of past forecast errors provides further information about unanticipated transmission shocks, although few central banks are forthcoming in this respect. Evaluation of monetary policy outcomes has risen from one-third to almost two-thirds of central banks, although the quality of it varies. ${ }^{3}$ The Swedish Riksbank stands out for publishing an elaborate 'account of monetary policy' once a year, including a rigorous analysis of its (forecast) performance.

Table 1 reveals that the rise in information disclosure has not been uniform throughout the 1998-2010 period. It was (often considerably) larger during 19982004 than 2004-2010, except for the publication of minutes and voting records, which picked up speed in the second half of the sample period. ${ }^{4}$

The large increase in transparency during the first half of the sample period is mainly driven by the advance of inflation targeting in emerging economies. ${ }^{5}$ However, transparency has risen for other monetary frameworks as well. This is illustrated in Figure 2, which shows the average of the Eijffinger-Geraats index (which ranges from 0 to 15) from 1998 to 2010, across all central banks and for inflation targeting, monetary targeting, exchange rate targeting and other frameworks, using the IMF classification of de facto monetary policy frameworks for

\footnotetext{
${ }^{3}$ An independent evaluation is useful, like the annual Norges Bank Watch report in Norway.

${ }^{4}$ This pattern still holds if the four (relative transparent) eurozone entrants are excluded from the entire sample. But the apparent slight decline in the evaluation of monetary policy outcomes from 2004 to 2010 then disappears and becomes a slight increase.

${ }^{5}$ This includes Brazil, Colombia, Czech Republic, Hungary, Mexico, Peru, Philippines, Poland, South Africa, South Korea, Thailand and Turkey.
} 
Figure 2: Transparency trends across monetary policy frameworks

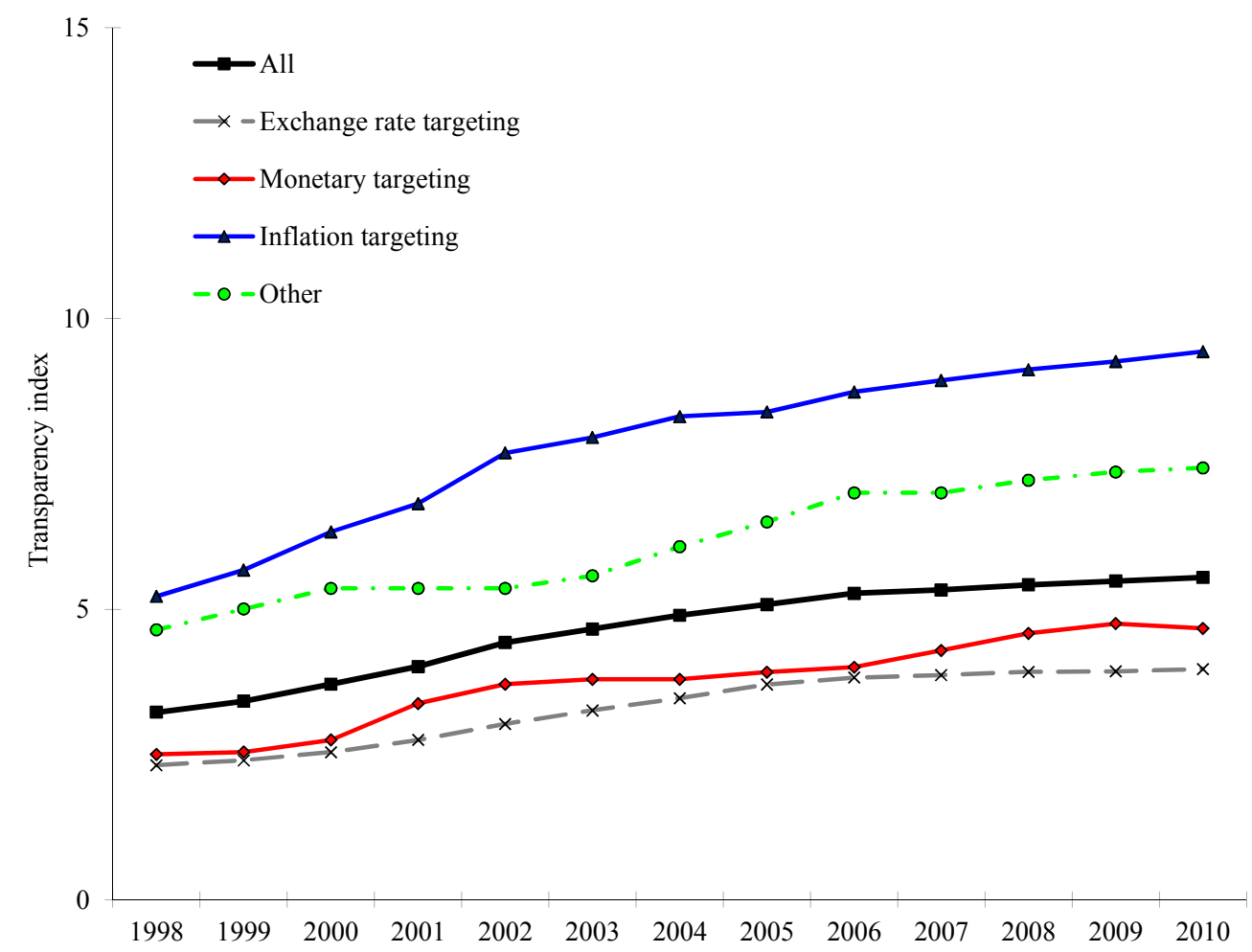

Note: Average Eijffinger-Geraats transparency index across 120 central banks using Dincer and Eichengreen (2013) data and IMF de facto classification of monetary policy frameworks for 2008. Sample size declined as 4 joined eurozone. Classification missing for 5.

2008 and the Dincer and Eichengreen (2013) transparency dataset. ${ }^{6}$

Figure 2 shows that inflation targeters are the most transparent and have experienced the greatest increase (of almost 25\%) in the Eijffinger-Geraats transparency index from 1998 to 2010. Monetary targeters, exchange rate targeters and others are considerably less transparent, but they have also experienced a notable increase. Clearly, the rise in monetary policy transparency has been a world-wide phenomenon across monetary policy frameworks.

\footnotetext{
${ }^{6}$ From the sample of 120 central banks, the IMF categorized 32 as inflation targeters (mostly advanced and emerging economies), 12 as monetary targeters (typically developing countries), 64 as exchange rate targeters (including many very small open economies), and 7 as 'other' (including India, Japan and United States). No IMF classification is available for the remaining 5 (Bermuda, Cayman Islands, Cuba, Curacao, Macao) or for more recent years.
} 
Nevertheless, central banks differ considerably in the way in which they have become more transparent. For instance, inflation targeters tend to put strong emphasis on improving economic transparency, whereas monetary targeters consider operational transparency more important. Further evidence of significant differences in information disclosure across monetary policy frameworks is provided by Geraats (2009).

To sum up, although monetary policy frameworks differ considerably in their information disclosure practices, they have all experienced a substantial increase in transparency. Overall, the greatest gains have been in economic and policy transparency. The more extensive disclosure of information by central banks has generally gone well beyond formal accountability requirements, which suggests that central banks have adopted transparency because of its perceived benefits.

\section{Macroeconomic Transparency}

To better understand the effects of transparency about the macroeconomic environment, it is useful to consider a stylized static model. ${ }^{7}$ Suppose the central bank maximizes the expected value of the objective function

$$
W=-\frac{1}{2} \alpha\left(\pi-\pi^{*}\right)^{2}-\frac{1}{2}(1-\alpha)(y-\bar{y})^{2}
$$

where $\pi$ denotes inflation, $y$ aggregate output, $\pi^{*}$ the central bank's inflation target, $\bar{y}$ the natural rate of output, and $\alpha$ the relative weight on inflation stabilization, with $\alpha \in(0,1)$. The economy is described by an expectations-augmented Phillips equation:

$$
\pi=\pi^{e}+(y-\bar{y})+s
$$

where $\pi^{e}$ denotes private sector inflation expectations, and $s$ is a cost-push or aggregate supply shock. In addition, there is an aggregate demand equation:

$$
y=\bar{y}-(r-\bar{r})+d
$$

where $r$ denotes the real interest rate, which (for the moment) is assumed to be the central bank's policy instrument; $\bar{r}$ the natural real interest rate, and $d$ is an

\footnotetext{
${ }^{7}$ Although the model assumes a closed economy, many of its insights apply more generally.
} 
aggregate demand shock. Suppose for simplicity that the central bank has perfect information, whereas the private sector initially faces opacity and does not observe the central bank's inflation target $\pi^{*}$ or the macroeconomic shocks $s$ and $d$, which are white noise. Then, the optimal policy rate under discretion equals

$$
r=\bar{r}+\alpha\left(\pi^{e}-\pi^{*}\right)+\alpha s+d
$$

This shows that the policy rate reflects both the central bank's inflation intentions $\pi^{*}$ as well as the macroeconomic shocks $s$ and $d$ anticipated by the central bank. The corresponding outcome for inflation is

$$
\pi=\pi^{e}+\alpha\left(\pi^{*}-\pi^{e}\right)+(1-\alpha) s
$$

So the policy outcome also reflects the central bank's intention $\pi^{*}$ and the supply shock $s$ that the central bank anticipates. If the central bank does not enjoy perfect foresight, then the inflation outcome is also affected by unanticipated shocks to aggregate demand and supply.

Note that presuming private sector expectations are rational, the (credible) announcement of the inflation target $\pi^{*}$ would align private sector inflation expectations with the inflation target: $\pi^{e}=\pi^{*}$. This makes it easier to achieve the inflation target, leading to a beneficial information effect, as shown by Geraats (2007a) in a more general model with imperfect common knowledge.

Greater transparency about macroeconomic shocks has several effects. First of all, it reduces private sector uncertainty. In particular, if the central bank publishes its inflation forecast (a prominent form of economic transparency), then the private sector will benefit from lower forecast errors $\left(\pi^{e}=\pi\right)$, constituting a positive information effect.

If the central bank discloses the aggregate supply shock $s$ it anticipates before the private sector has formed its expectations, however, then the adjustment of inflation expectations $\pi^{e}$ leads to higher inflation volatility. In that case, (5) implies $\pi^{e}=\pi=\pi^{*}+\frac{1-\alpha}{\alpha} s$, so $\operatorname{Var}[\pi]=\frac{(1-\alpha)^{2}}{\alpha^{2}} \sigma_{s}^{2}$ under economic transparency, compared to $\operatorname{Var}[\pi]=(1-\alpha)^{2} \sigma_{s}^{2}$ under opacity, where $\sigma_{s}^{2}=\operatorname{Var}[s]$ denotes the variance of the supply shock $s$. Thus, economic transparency could have a negative information effect by making inflation more volatile, as first shown by Cukierman (2001) and Gersbach (2003). 
In addition, the publication of macroeconomic forecasts gives rise to incentive effects. If the central bank provides its forecasts for both inflation $\pi$ and output $y$, then the private sector can identify the aggregate demand and supply shocks $d$ and $s$ anticipated by the central bank (from (2) and (3)), which allows the private sector to infer the central bank's inflation intentions $\pi^{*}$ from its policy action $r$ (using (4)). ${ }^{8}$ Note that this presumes that economic transparency extends to the macroeconomic model (including $\bar{y}$ and $\bar{r}$ ) used by the central bank for its forecasts and policy actions, which shows the importance of publishing the policy model. ${ }^{9}$

Because economic transparency allows the public to figure out the central bank's policy intentions from its policy actions, a central bank pursuing inflationary policy would quickly be exposed, leading to higher inflation expectations $\pi^{e}$, which is detrimental to the central bank as it worsens the inflation-output trade-off (2). Thus, an inflationary central bank is penalized under economic transparency, which exerts discipline on the central bank and provides a positive incentive effect. This reduces the infamous inflation bias in a dynamic setting, as shown by Geraats (2005). When the updating of inflation expectations is incorporated into the monetary policy transmission process, economic transparency could even completely eliminate the inflation bias (Geraats 2001).

Furthermore, the monetary policy rate $r$ essentially serves two purposes: it provides a (noisy) signal of the central bank's policy intentions $\pi^{*}$, and it is used to stabilize macroeconomic shocks $s$ and $d$ (as shown by (4)). When the central bank suffers from economic opacity, an adjustment of the policy rate in response to a macroeconomic shock (e.g. reducing rates for a negative demand shock) could be confused with a change in policy intentions and thereby affect private sector inflation expectations (increasing them in this case). So, an opaque central bank optimally decides to limit stabilization policy and no longer fully offsets aggregate demand shocks it anticipates, to mitigate upsetting inflation expectations. With economic transparency, however, the central bank effectively has an additional tool through the communication of its forecasts, which gives it the flexibility to

\footnotetext{
${ }^{8}$ In an open economy, a forecast for the exchange rate would be needed as well. The Czech central bank has published a fan chart of its forecast of the nominal exchange rate (against the euro) since 2009, in addition to its fan charts for inflation and output growth.

${ }^{9}$ This could be partly addressed by using the output gap $(y-\bar{y})$ instead. The central bank of Norway introduced a fan chart of its output gap forecast in 2005.
} 
engage in macroeconomic stabilization while maintaining stable inflation expectations. This beneficial incentive effect was first formalized by Geraats (2000) and further analyzed by Walsh (2007) and Geraats (2013).

Economic transparency is also important because it enables real-time accountability. Monetary policy actions generally affect policy outcomes only after long and variable lags in monetary policy transmission, which means that holding central bankers accountable ex post requires a delay of a few years to check whether they have achieved their policy objectives. But economic transparency allows the public to infer the central bank's intentions from its policy actions, which makes it possible to hold central bankers accountable for their actions in real time and verify whether their monetary policy decisions are consistent with their stated objectives. $^{10}$

When the central bank has an explicit inflation target, its inflation forecasts are not only useful for reducing uncertainty about the policy outcome, but also for explaining its policy action. In special circumstances, the central bank's inflation forecast can even serve as a sufficient statistic for its policy rate decision (Svensson 1997). More generally, under inflation targeting the inflation forecast could be considered as an intermediate target that indicates whether policy is on track. Furthermore, since inflation can only be controlled imperfectly after a long transmission lag (often about two years), communication of medium term macroeconomic forecasts is vital to understanding policy rate actions. This helps to explain why economic transparency is so prevalent among inflation targeters.

Operational transparency also requires openness about macroeconomic information, but instead of releasing anticipated shocks (e.g. through forecasts) that help to explain policy actions, it involves the communication of unanticipated disturbances (e.g. through forecast errors) that help to account for policy outcomes. When the central bank has perfect information, the outcomes for inflation $\pi$ and output $y$ reveal the central bank's policy intention $\pi^{*}$ to the public (using (2) and (5)). In practice, however, the central bank is unable to fully anticipate all macroeconomic shocks, so the policy outcomes are a noisy signal of the central bank's intentions. The central bank could overcome this by identifying shocks it did not

\footnotetext{
${ }^{10}$ Real-time accountability could be undesirable if the central bank lacks independence and is subject to government interference, in which case economic opacity may be used to fend off political pressures (Geraats 2007b).
} 
anticipate, so that the public is still able to infer the central bank's intentions from macroeconomic outcomes.

Operational transparency would therefore expose any central bank pursuing inflationary policy ex post. The private sector would then increase its inflation expectations, thereby worsening the inflation-output trade-off for the central bank. Hence, operational transparency gives rise to a positive incentive effect that could reduce the inflation bias, as shown by Faust and Svensson (2001).

But the disclosure of control errors or unanticipated transmission shocks could also have detrimental effects. In particular, if the central bank reveals supply shocks $s$ that it failed to anticipate when setting policy and the public incorporates these into its inflation expectations $\pi^{e}$ so that it affects the inflation outcome $\pi$, then this gives rise to higher inflation volatility. Thus, operational transparency (especially before the policy outcome has been realized) could have a negative information effect by harming the stabilization of supply shocks, as shown by Jensen (2002).

It should be noted, however, that detrimental information effects of supply shocks under (economic or operational) transparency require that the shocks are persistent or disclosed before people form their inflation expectations. In practice, supply shocks tend to be transitory and hard to anticipate, which suggests that these negative information effects of macroeconomic transparency may be moot.

Operational transparency facilitates ex post accountability, because it explains why policy outcomes may not be as intended. This is particularly useful in a world in which macroeconomic uncertainty is rife or the monetary transmission mechanism is prone to disturbances. This may explain why monetary targeters tend to put relatively more emphasis on operational transparency; it helps them cope with their imperfect control of monetary aggregates. In addition, since monetary targeters are predominantly developing countries, they may face challenges implementing transparency (such as constructing numerical macroeconomic forecasts), which helps to account for their relative opacity.

Note that the model in this section has assumed that the central bank conducts monetary policy under discretion. In practice, however, central banks may lack discretion, in particular when they maintain an exchange rate peg. In that case, the information effects still hold, but the beneficial incentive effects no longer apply. This could explain why exchange rate targeters tend to be more opaque. 
There is empirical support for the theoretical findings discussed in this section. An explicit and credible inflation target indeed helps to anchor long-run inflation expectations, as shown by Gürkaynak, Levin and Swanson (2010). Similarly, Van Der Cruijsen and Demertzis (2007) find that greater overall transparency leads to more stable private sector inflation expectations and less inflation persistence.

Using the Fry et al. (2000) survey data, Chortareas, Stasavage and Sterne (2002) find that average inflation is significantly decreasing in the extent to which central banks publish forward-looking analysis and forecasts, controlling for institutional and macroeconomic characteristics (e.g. central bank independence, GDP per capita, openness). But this does not hold for countries with an exchange rate peg, which is consistent with the theory behind beneficial incentive effects. Chortareas, Stasavage and Sterne (2003) show that higher macroeconomic transparency also reduces the 'sacrifice ratio' (i.e. the output cost of disinflation).

Geraats, Eijffinger and Van Der Cruijsen (2006) find that increases in transparency, taken from the Eijffinger and Geraats (2006) dataset, are often followed by significantly lower (short or long-term) nominal interest rates, controlling for macroeconomic conditions, suggesting greater flexibility and reputation.

Dincer and Eichengreen (2013) use their own extensive panel dataset to first find determinants of transparency (which include GDP per capita, financial depth, openness and governance indicators), and then estimate the effects of monetary policy transparency using governance indicators as instruments to take into account endogeneity. They show that greater transparency tends to significantly reduce inflation variability and also lower the level of inflation.

To summarize, transparency about macroeconomic information generates a beneficial information effect as it reduces private sector uncertainty about the economy. Furthermore, economic and operational transparency both allow the private sector to better understand the central bank's inflationary intentions, so they help to anchor long-run inflation expectations. Economic transparency helps the public to infer the central bank's intentions from its policy actions, enabling ex ante accountability, whereas operational transparency allows inference based on policy outcomes, facilitating ex post accountability. As a result, providing macroeconomic transparency is useful for central banks to maintain low inflation and stable inflation expectations. This helps to explain why it has become such an important feature of monetary policymaking. 


\section{Forward Policy Guidance}

Most central banks nowadays promptly announce any adjustments in their policy settings. However, this provides an incomplete description of the monetary policy stance. First of all, the monetary policy instrument is typically only adjusted in discrete steps (such as 25 basis points for the policy rate). This means that central bankers often decide not to adjust their policy settings. For instance, they may judge that macroeconomic developments point to a rise in the policy rate of 10 basis points, but that moving by an entire step is not (yet) warranted, so they decide not to change the policy rate. Simply announcing the policy decision thus hides the actual policy inclination towards increasing the rate. As a result, providing information about the policy inclination is an important part of policy transparency.

The policy inclination may be revealed through voting records (if they are released). For example, dissents in favor of raising the policy rate indicate a bias towards tightening and could foreshadow an upcoming rate hike. But, such dissents may also be due to persistent heterogeneity in policy preferences and reflect the presence of inflation-averse 'hawks'. In addition, if the vote was unanimous (e.g. not to change the policy rate), then it could still be the case that central bankers had a policy inclination (e.g. towards tightening, as above). Thus, voting records need not be a good indicator of the likely direction of upcoming policy moves.

The minutes of the policy deliberations could provide better clues about the policy inclination. In particular, the minutes could reveal which policy options were discussed. For instance, if the discussion focused on whether to change the policy rate by 0 or +25 basis points, then this indicates a policy inclination towards tightening. But the minutes are only available after a considerable delay (if at all), so they cannot provide a prompt signal of the policy inclination.

As a result, the publication of minutes and/or voting records is not a substitute for providing an explicit policy inclination. Releasing a policy announcement with a qualitative indication of the likely direction of the next policy move would contribute to policy transparency, although a full description of the monetary policy stance requires quantitative information about the projected path of the policy instrument. 
To understand why the monetary policy stance is inherently forward-looking, it is useful to go back to the stylized model in section 4. It was assumed that the central bank directly controls the real interest rate $r$ that drives aggregate demand. However, in reality the policy rate is a very short term (nominal) interest rate that on its own has little impact, but influences the longer-term interest rate that matters for aggregate demand. In particular, assuming the expectations theory of the term structure, the longer-term rate $r_{t}$ is determined by current and expected future policy rates:

$$
r_{t}=\frac{1}{T} \sum_{s=0}^{T-1} \rho_{t+s \mid t}^{e}
$$

where $\rho_{t+s \mid t}^{e}$ denotes the (real) policy rate in period $t+s$ expected in period $t$, and $T$ is the term of the (real) interest rate $r_{t}$ (in terms of that of the policy rate, which may be overnight). ${ }^{11}$ According to (6), the interest rate $r_{t}$ that aggregate demand depends on is hardly affected by the current policy rate $\rho_{t}$, but predominantly by the expected path of future policy rates $\rho_{t+s \mid t}^{e}$. So, macroeconomic projections require an assumption about expected future policy settings. In particular, if the interest rate $r_{t}$ relevant for aggregate demand is, say, a three-year rate, then the expectation of policy rates over a three-year horizon is needed. Likewise, the impact of a monetary policy decision depends critically on expected future policy settings. For instance, the effect of a reduction in the policy rate is stronger if it is anticipated to last longer. So, the current policy rate is not sufficient to describe how stimulatory monetary policy is because the central bank's plans for future policy rates are needed as well to assess this. The projected policy path is therefore an integral part of the monetary policy stance.

This result holds even more strongly in the New Keynesian model which features a forward-looking Phillips curve and IS equation. ${ }^{12}$ The New Keynesian Phillips curve is given by

$$
\pi_{t}=\beta \mathrm{E}_{t}\left[\pi_{t+1}\right]+\kappa \tilde{y}_{t}
$$

where $\tilde{y}_{t} \equiv y_{t}-\bar{y}_{t}$ denotes the output gap, and $\beta$ and $\kappa$ are constant, positive parameters (with $\beta$ equal to the intertemporal discount factor for lifetime utility,

\footnotetext{
${ }^{11}$ This presumes that prices are sticky in the short run so that the central bank is effectively able to control the short-term real interest rate.

${ }^{12}$ For a derivation and discussion of the New Keynesian model, see Galí (2008).
} 
satisfying $0<\beta<1$ ). The dynamic, optimizing IS equation is described by

$$
\tilde{y}_{t}=\mathrm{E}_{t}\left[\tilde{y}_{t+1}\right]-\gamma \tilde{r}_{t}
$$

where $\tilde{r}_{t} \equiv r_{t}-\bar{r}_{t}$ denotes the real interest rate gap (relative to the natural real interest rate $\bar{r}_{t}$ ), and $\gamma$ is a constant, positive parameter (which represents the intertemporal elasticity of substitution and is equal to the inverse of the coefficient of relative risk aversion). Forward substitution of (8) yields

$$
\tilde{y}_{t}=-\gamma \sum_{k=0}^{\infty} \mathrm{E}_{t}\left[\tilde{r}_{t+k}\right]
$$

Thus, not just the current real interest rate (gap) $\tilde{r}_{t}$ but the entire path of expected real interest rates drives aggregate demand. As a result, the projected policy path over an infinite horizon would be required to fully specify the monetary policy stance in the New Keynesian model.

Nevertheless, the central bank could use private sector expectations of future policy rates (from surveys or implied by market interest rates) to form macroeconomic projections and use these to decide whether to adjust its current policy rate. When its policy decision is not fully anticipated by the private sector, however, these macroeconomic projections are not appropriate because private sector expectations of the interest rate path will be updated. The central bank could try to model how the private sector is likely to adjust its expectations, but it would be challenging to predict the private sector response to policy surprises. Alternatively, the adjustment of private sector expectations could be considered as an expectational shock or control error. In particular, (6) could be rewritten as $r_{t}=\frac{1}{T} \rho_{t}+v_{t}$, where $v_{t} \equiv \frac{1}{T} \sum_{s=1}^{T-1} \rho_{t+s \mid t}^{e}$ is an expectational disturbance. This shows that the central bank has imperfect control over the economically relevant interest rate $r_{t}$ due to changes in private sector expectations.

Instead of passively considering adjustments in expectations as control errors, however, the central bank has the opportunity to actively influence private sector expectations through its communications and thereby improve monetary control. In particular, the central bank could engage in the 'management of expectations' (Woodford 2005) by disclosing information about its projected policy path. Thus, forward policy guidance gives the central bank an additional tool to enhance the effectiveness of monetary policy. 
Most central banks provide at least some general guidance by publishing their monetary policy strategy, which broadly describes how policy tends to respond (e.g. for inflation targeting, adjusting the policy rate upward/downward if the medium term forecast for inflation is above/below the inflation target). The central bank's macroeconomic projections (e.g. for inflation) then provide an indication of policy prospects. Economic and operational transparency also help the private sector to learn the monetary policy response over time using policy actions and outcomes. The release of voting records, besides indicating a policy bias, makes this learning process more efficient as the degree of unanimity of the vote can be used to weigh the observations. ${ }^{13}$ Publication of the minutes of policy meetings discloses further detail about the considerations of policymakers, for instance by identifying which economic and financial variables are considered particularly important for the policy decision. Speeches by central bankers could provide additional background. Such general guidance contributes to understanding the monetary policy reaction, but it often leaves considerable uncertainty.

To improve the predictability of policy actions and enhance the management of expectations, central banks could give specific forward guidance about the likely timing, direction, size and/or pace of upcoming policy moves. Although this may be communicated in the minutes or central bankers' speeches, it is most notably expressed in a statement accompanying the policy decision.

Forward guidance could be confined to qualitative assessments conveyed by code words or particular phrases (like the Federal Reserve's 'measured' pace and 'extended period', or the ECB's use of 'strong vigilance'). ${ }^{14}$ Such code-word communication can be very flexible but has the drawback that its precise meaning may not be (immediately) clear, impeding its effectiveness.

Greater transparency is achieved by providing quantitative guidance on how future policy is likely to be adjusted depending on time or economic conditions. A simple form of time-dependent forward guidance specifies a date until which policy is likely to be maintained. For example, the Reserve Bank of New Zealand

\footnotetext{
${ }^{13}$ When individual voting records are disclosed, they could also be used to infer central bankers' possibly heterogeneous preferences, as modeled by Weber (2010). This has the additional advantage of improving accountability, as it allows the government to re-appoint only those with desirable preferences, which could induce central bankers to act accordingly (Gersbach and Hahn 2004).

${ }^{14}$ The latter signals an imminent rate hike (see Geraats, Giavazzi and Wyplosz 2008, box 6).
} 
wrote in its policy statement of 9 March 2006 that "we do not expect to be in a position to ease policy this year" (contrary to market expectations); and the Bank of Canada announced on 21 April 2009 to expect its policy rate to remain low at $0.25 \%$ "until the end of the second quarter of 2010". Such calendar-based guidance provides clarity, although a fixed date reduces flexibility, so it may be desirable to adjust the date as circumstances change. ${ }^{15}$ It has been argued that the latter could be counterproductive (Woodford 2012). In particular, extending the duration of ultra-low policy rates may be interpreted as bad news about macroeconomic prospects (rather than a more expansionary monetary policy stance) and therefore further depress economic activity instead of stimulating it, constituting a negative information effect. The problem is that time-dependent guidance provides a noisy signal that reflects both policy preferences and anticipated macroeconomic shocks. But if the central bank reveals its views about the latter (e.g. by publishing its macroeconomic forecasts), confusion can be prevented.

Instead of a fixed date, forward guidance could stipulate specific economic conditions for a policy adjustment using a quantitative threshold. A few central banks have adopted such state-contingent guidance based on a threshold for inflation (Japan) or the unemployment rate (United States and United Kingdom). For instance, to stem deflationary expectations the Bank of Japan announced in its monetary policy statement of 19 March 2001 that its new 'quantitative easing' policy would continue until the consumer price index (CPI, excluding perishables) increases by at least $0 \% .{ }^{16}$ The Federal Reserve indicated in its policy statement of 12 December 2012 that it expected to keep the policy rate close to zero at least as long as the unemployment rate remains above $6.5 \% .^{17}$

State-contingent forward guidance generates flexibility as its implied policy settings move in line with the state of the economy (e.g. effectively extending the horizon for low policy rates when economic conditions deteriorate). In fact,

\footnotetext{
${ }^{15}$ The Federal Reserve's forward guidance of 9 August 2011 indicating an 'exceptionally low' policy rate "at least through mid 2013" was twice modified to extend the minimum horizon to "late 2014' in January 2012 and to 'mid 2015' in September 2012.

${ }^{16}$ In addition, the Bank of Japan's policy statement of 4 April 2013 announced that its new policy of 'quantitative and qualitative monetary easing' will continue "as long as it is necessary" to achieve its 'price stability target' of $2 \%$ CPI inflation.

${ }^{17}$ The Bank of England's forward guidance announced on 7 August 2013 is similar but features an unemployment rate threshold of $7 \%$.
} 
it could act as an automatic stabilizer as the adjustment of market rates generates more/less stimulus when private sector prospects worsen/improve. On the other hand, its dependence on future economic conditions makes the timing of policy moves more uncertain under state-contingent guidance, which reduces its effect on longer-term interest rates. Different views about economic prospects could also make it less effective. For example, the Bank of England believed that its unemployment rate threshold of $7 \%$ would be reached in three years, but if the private sector expects it to be hit much earlier, then the state-dependent guidance leads to a higher level of medium-term interest rates than intended, making it less stimulatory. Furthermore, the choice of the threshold in state-contingent guidance could be problematic. In particular, if the threshold for the unemployment rate is (unwittingly) set below the natural rate of unemployment, then forward guidance will fuel inflation. This could be overcome by including escape clauses. For example, the Federal Reserve's unemployment threshold guidance is conditional on medium-term inflation projections being below $2.5 \%$ and long-term inflation expectations remaining well-anchored. ${ }^{18}$

The most sophisticated form of forward guidance used by central banks is to publish the projected policy path. This provides a comprehensive time-dependent description of the monetary policy stance, specifying the likely timing, direction, size and pace of future policy actions. The Reserve Bank of New Zealand has published its projected interest rate path since 1997. ${ }^{19}$ It has been followed by Norway (since 2005), Sweden (since 2007), Iceland (2007-2008), the Czech Republic (since 2008) and the United States (since 2012). ${ }^{20}$ The projected path for the interest rate is generally presented in a fan chart that illustrates the underlying uncertainty. The projections are based on specific assumptions about economic developments that may be explicitly stated. This conditionality could be further clarified using scenario analysis that shows how the interest rate path would be affected by particular plausible circumstances (such as higher wage demands),

\footnotetext{
${ }^{18}$ The Bank of England's unemployment threshold guidance is subject to three 'knockouts' pertaining to maintaining not only price stability (similar to the Fed), but also financial stability.

${ }^{19}$ It also provided its projected path for the Monetary Conditions Index (MCI) while the MCI was used as its policy instrument until 1999.

${ }^{20}$ Norway, Sweden, (Iceland) and the United States release(d) the projected path of their policy rate, but New Zealand and the Czech Republic the path of a closely related three-month rate. Iceland stopped publishing its policy path during its acute financial crisis.
} 
thereby providing some state-contingent guidance as well. An excellent example is the Swedish Riksbank, which has published its projected policy path together with scenario analysis since 2007.

Another way to clarify how monetary policy is likely to respond is to reveal how the projected policy path is chosen. The central bank of Norway has gone furthest in this respect by identifying its criteria and even formalizing them in the form of a loss function (similar to (1) but with two additional terms pertaining to the interest rate). However, it stresses that the "loss function [...] must be regarded as a simplified representation of the more extensive assessments behind interest rate decisions." ${ }^{21}$ Although disclosing the loss function may be enlightening to economists, it is unlikely to be very illuminating to the general public, doing little to reduce their uncertainty about future interest rates.

A potential alternative would be to specify how policy settings respond to economic conditions by directly divulging the monetary policy reaction (like (4)). That would provide a comprehensive form of state-dependent forward guidance. In practice, however, monetary policy decisions depend on so many different, often unforeseen factors and finely balanced judgments, that it is virtually impossible to fully describe them. Even if a central bank actually managed to formulate its monetary policy reaction function, its state-contingency would still leave the public uncertain about the likely time path of the policy instrument, reducing its effectiveness. So it would be useful to complement the state-contingent guidance by projections of the policy path.

To summarize this discussion of different forms of forward guidance, timedependent policy guidance has the advantage of directly providing information about the future policy path, which makes it easier for the central bank to manage expectations, whereas state-contingent forward guidance has the benefit of offering greater flexibility. As a result, it would be desirable to give forward guidance that combines state-contingent and time-dependent features. In particular, timedependent policy guidance is enhanced by adding some state-contingency (e.g. through escape clauses or scenario analysis). Similarly, state-contingent forward guidance benefits from being supplemented by the projected policy path.

\footnotetext{
${ }^{21}$ Norges Bank Monetary Policy Report 2/2010, p. 23. See also Norges Bank Monetary Policy Report 1/2012, Box "Response pattern of monetary policy and criteria for an appropriate interest rate path" (pp. 15-16).
} 
In general, forward guidance is useful because it reduces uncertainty about upcoming policy decisions and allows the central bank to influence expectations of the policy rate in line with its intentions. Thus, the central bank has better control over longer-term interest rates (based on (6)), which makes monetary policy more effective. Forward guidance also provides a signal of the inflationary preferences of the central bank, which facilitates the alignment of inflation expectations as well. These information effects, which have been modeled by Rudebusch and Williams (2008), generally improve macroeconomic performance.

If the central bank has noisy information about economic shocks, however, then publication of its interest rate forecast could lead private sector expectations astray and be welfare reducing. This detrimental information effect is illustrated in the model by Gosselin, Lotz and Wyplosz (2008), who find that releasing the central bank's interest rate forecast is welfare improving if its information is sufficiently precise compared to the private sector.

Although the central bank's forward guidance may be noisy, it is generally still informative so it allows the private sector to improve its forecasts. This reduction in private sector uncertainty stemming from transparency is likely to lower risk premia, which cuts the cost of capital, thereby stimulating investment and growth, as argued by Begg (2006). This beneficial information effect could be formalized by assuming that, instead of the expectations theory of the term structure in (6), the interest rate $r_{t}$ is determined by both expected future policy rates $\rho_{t+s \mid t}^{e}$ and a term premium $\theta_{t}$ that reflects interest rate and liquidity risks:

$$
r_{t}=\frac{1}{T} \sum_{s=0}^{T-1} \rho_{t+s \mid t}^{e}+\theta_{t}
$$

Forward guidance about the policy rate makes future interest rates less uncertain, reducing the risk premium $\theta_{t}$. In the case of unconventional monetary policy such as 'quantitative easing', forward guidance could have a similar effect on $\theta_{t}$ by lowering liquidity premia.

Furthermore, in the New Keynesian model forward guidance facilitates the implementation of optimal monetary policy, which involves commitment to a history-dependent, state-contingent policy path (e.g. Woodford 2005). The key role of commitment is to affect private sector expectations about future inflation and output, which have a powerful effect on current inflation and output in the 
New Keynesian model described by (7) and (8). Communications about future policy allow the central bank to have a similar effect and improve the effectiveness of monetary policy. For instance, forward guidance to keep the nominal interest rate low for longer raises expected future inflation and output, thereby increasing current inflation and output in the New Keynesian model. Even if the nominal interest rate $i_{t}$ is at its lower bound, the rise in expected future inflation provides further stimulus by reducing the real interest rate $r_{t}$, using the Fisher parity

$$
i_{t}=r_{t}+\mathrm{E}_{t}\left[\pi_{t+1}\right]
$$

Thus, forward guidance gives central banks an additional policy tool that could overcome the lower-bound constraint on the nominal interest rate (as discussed by Bernanke, Reinhart and Sack (2004) and Woodford (2005 and 2012)).

Likewise, the publication of interest rate projections could have a beneficial effect on private sector expectations during more usual times. Gersbach and Hahn (2011) show that it is welfare improving for the central bank to announce interest rate projections in a New Keynesian model with supply shocks, provided it is costly for the central bank to deviate from these projections. The latter gives the central bank an incentive to set the interest rate close to its projections, which has a similar beneficial effect on expectations as commitment.

Publishing the projected policy path could also help to overcome a timeinconsistency problem associated with commonly used monetary policy strategies that aim to achieve the policy objective (e.g. inflation target) by the end of a particular policy horizon (e.g. two years). Since the central bank's policy horizon moves along as time passes (e.g. always two years ahead), policy is adjusted over time (even in the absence of further shocks) and the target reached too slowly. ${ }^{22}$ This time-inconsistency issue can be overcome by following the (initial, optimal) projected policy path and only deviating from it in response to new information (just like optimal policy in the New Keynesian model). Announcement of the projected policy path is likely to induce the central bank to do so as discrepancies would demand explanation, thereby preventing persistent deviations from target and making medium-term inflation expectations more stable.

\footnotetext{
${ }^{22}$ If the policy horizon is two years and an adverse shock pushes inflation above its target in year $t$, then policy is tightened to reach the target in year $t+2$. But in the next year $t+1$, policy is adjusted to achieve the target in year $t+3$ instead, contrary to the central bank's intentions in year $t$. See Bjørnland, Ekeli, Geraats and Leitemo (2004, chapter 3) for a further discussion.
} 
An important issue is whether the central bank should commit to its forward guidance. A credible commitment allows the central bank to improve control over longer term (nominal) interest rates. For instance, by credibly committing to keeping the policy rate near zero for the next three years, the central bank could steer the three-year nominal interest rate close to zero (assuming (6)), thereby making the monetary stimulus more effective. However, this comes at the cost of losing flexibility to respond to unforeseen circumstances arising in the future. Although this is particularly problematic for time-dependent forward guidance, ${ }^{23}$ even statecontingent guidance with its built-in flexibility cannot overcome the immutable nature of a commitment since it is practically impossible to take into account all possible contingencies. Furthermore, central banks face considerable uncertainty not only about (the type of) future shocks (e.g. 9/11 attacks or Lehman Brothers' collapse), but also about the (possibly changing) structure of the economy. Thus, commitment to policy guidance inevitably leads to a credibility-flexibility tradeoff, with greater credibility enhancing the effectiveness of current policy, but the lack of flexibility limiting future monetary policy. ${ }^{24}$

In practice, forward guidance usually refrains from making an absolute commitment. An exception is the Bank of Japan, which made explicit, state-contingent 'policy duration' commitments without qualifications in 1999 and 2001. ${ }^{25}$ To maintain future flexibility, forward guidance tends to be formulated using verbal qualifiers (such as 'likely') or explicit caveats (like the Fed's conditions on inflation forecasts and expectations in its unemployment threshold guidance). A good example is the explicit 'conditional commitment' announced by the Bank of

\footnotetext{
${ }^{23}$ In fact, committing to a fixed level or time path of the nominal interest rate $(\bar{\imath})$ is actually destabilizing. For instance, an inflationary shock that raises inflation expectations $\pi^{e}$ reduces the real interest rate $r=\bar{\imath}-\pi^{e}$, leading to even higher inflation.

${ }^{24}$ For a discussion of 'Odyssean' policy guidance that publicly commits the central bank versus 'Delphic' forward guidance that merely provides a forecast, see Campbell, Evans, Fisher and Justiniano (2012).

${ }^{25}$ The Bank of Japan announced in its monetary policy statement of 21 September 1999 that it is "explicitly committed to continue [its zero interest rate] policy until deflationary concerns subside". In addition, the minutes of its monetary policy meeting of 19 March 2001 explicitly refer to the 'policy duration commitment' (to continue 'quantitative easing') in its $0 \%$ inflation threshold guidance. Although the Bank of Japan has also explicitly committed to pursue 'quantitative and qualitative monetary easing' in its $2 \%$ inflation threshold guidance of 4 April 2013, it added the qualification to "make adjustments as appropriate".
} 
Canada on 21 April 2009 that "conditional on the outlook for inflation", its policy rate "can be expected" to remain at $0.25 \%$ "until the end of the second quarter of 2010"; this conditional commitment was removed on 20 April 2010 and the policy rate was actually raised on 1 June 2010. Similarly, by presenting policy path projections in a fan chart central banks clearly show that they are a forecast, not a promise. However, forward guidance with such qualifications or escape clauses may be harder to understand and increases uncertainty about future policy settings, making it less effective at influencing private sector expectations.

Nevertheless, forward guidance generally entails some kind of commitment, not to follow specific policy settings come what may, but to explain deviations. Although central banks that publish their policy rate projections routinely deviate from them, this is always accompanied by an explanation. The change could be in line with previous scenario analysis or due to unanticipated developments. The central bank of Norway provides the most rigorous account of changes in its projected policy path by formally decomposing them into different types of shocks. ${ }^{26}$ As a result, central banks maintain flexibility in their policy settings and forward guidance is foremost a commitment to transparency.

There are interesting empirical findings related to the effectiveness of forward guidance. First of all, there is strong evidence from financial market reactions that central bank communications are informative about interest rate prospects.

Assessing the contribution of policy statements is complicated by the fact that they are usually released together with the policy decision. To disentangle their effects, Gürkaynak, Sack and Swanson (2005) use high-frequency data on interest rate futures to decompose the effect of US monetary policy decisions into two independent factors, the current policy rate and the future path of policy. The latter appears strongly associated with Federal Reserve statements accompanying the policy announcement, and has a significant effect on medium- to long-term US Treasury yields. In fact, it has much greater explanatory power for longerterm yields than the current policy action, thus establishing the importance of the future policy path. ${ }^{27}$

\footnotetext{
${ }^{26}$ Published in its Monetary Policy Reports since October 2007 (e.g. "Changes in the projections since Monetary Policy Report 2/13”, Norges Bank Monetary Policy Report 3/13, pp. 22-23).

${ }^{27}$ Campbell et al. (2012) find that the path factor also significantly affects long-term corporate bond yields and continued to be important during the recent financial crisis.
} 
Using a similar factor decomposition based on high-frequency financial data, Bernanke et al. (2004) find that the factor capturing the policy path over a oneyear horizon is significantly affected by surprises in Federal Reserve statements, whether they pertain to the state of the economy or directly to the likely path of the policy rate. They estimate that a surprisingly 'hawkish' statement about the policy path increases five-year US Treasury yields by about 10 basis points.

The effect of policy statements can be directly identified for the European Central Bank, because its statements are made at a press conference held 45 minutes after the policy announcement. Using high-frequency data of short-term forward rates, Brand, Buncic and Turunen (2010) find that the ECB's statements provide news about the future policy path, which has a significant effect on interest rates across the euro area yield curve. Their results indicate that news stemming from the statements matters much more for medium- to longer term yields than news from the policy decision, which shows the importance of communications as an additional policy tool.

To identify what type of information is particularly relevant, Ehrmann and Fratzscher (2009) analyze minute-by-minute market reactions to the ECB's press conferences. They find that short-term interest rate futures respond most strongly to statements about inflation and the policy rate discussion (such as the policy options considered and the degree of unanimity about the decision).

The minutes of monetary policy meetings also generate significant intraday effects on financial markets, including on short- and long-term interest rate futures for the Bank of England (Reeves and Sawicki 2007), and on medium- to longterm interest rates, equity prices and exchange rates for the Federal Reserve (Rosa 2013). There is also a significant intraday effect on short-term interest rate futures for the Bank of England's Inflation Report (Reeves and Sawicki 2007).

Communications by individual monetary policymakers (e.g. speeches) also have the ability to move financial markets. For instance, for the Bank of England, European Central Bank and Federal Reserve, Ehrmann and Fratzscher (2007a) find that statements by individual policymakers about the economic outlook and the monetary policy inclination have a significant effect on market rates and equity prices in a direction that is in line with the statements' content. The frequency of such communications and the market responses to them tend to increase prior to adjustments in the policy rate (Ehrmann and Fratzscher 2007b). This suggests that 
policymakers effectively use inter-meeting communications to signal upcoming policy moves.

There are further empirical findings that central bank communications could make monetary policy decisions more predictable. For instance, voting records are informative about upcoming policy adjustments (e.g. Gerlach-Kristen 2004, Horváth, Šmídková and Zápal 2012). The same holds for the minutes of policy meetings (e.g. Apel and Grimaldi 2012). And countries that publish higher-quality inflation reports experience smaller financial market reactions to monetary policy decisions, indicating better predictability (Fracasso et al. 2003).

To establish whether transparency makes interest rates more predictable it is important to take into account economic conditions. Focusing on the United States, Swanson (2006) shows that controlling for macroeconomic shocks, shortrun private sector forecasts of short-term interest rates have become more accurate and less uncertain or dispersed, while forecasts of inflation and output growth have not improved. He also finds a significant decline in financial market uncertainty about short-term interest rates on monetary policy meeting days, but only since 1994, when the Federal Reserve started to announce and explain adjustments to its policy rate. This strongly suggests that the improvement in forecast performance for short-term interest rates is attributable to greater Federal Reserve transparency.

Moreover, there is interesting evidence on beneficial effects of specific forward policy guidance. The Federal Reserve's qualitative forward guidance between 1999 and 2004 (e.g. 'balance of risks') is analyzed by Ehrmann and Fratzscher (2007c), who show that it reduced market uncertainty about short-term interest rates on monetary policy meeting days. Market interest rates also adjusted less during the inter-meeting period, which appears to be due to smaller reactions to inter-meeting communications by individual policymakers. Although they find no change in the predictability of monetary policy decisions (compared to 19941999), financial markets anticipate policy actions earlier with policy guidance. This indicates that the qualitative forward guidance by the Federal Reserve has made the implementation of monetary policy more efficient.

Central bank communications could also greatly facilitate the operational implementation of monetary policy, which is usually conducted through open market operations. Guthrie and Wright (2000) analyzed how the Reserve Bank of New Zealand largely used announcements ('open mouth operations') to achieve its de- 
sired level of monetary conditions. They found significant effects on interest rates and exchange rates in the direction signaled by the announcements.

There is also empirical evidence on the effect of quantitative forward guidance. Moessner and Nelson (2008) find that the publication of interest rate projections by the Reserve Bank of New Zealand (RBNZ) has a significant effect on market rate expectations implied by futures prices for a horizon of two to six quarters ahead, although the magnitude of the estimated impact is small (with a coefficient of about 0.2). The latter could be due to measurement issues (as the relevant explanatory variable, the surprise in the RBNZ projections, is unobservable) or because the private sector has different views about the macroeconomic outlook. There is no sign that financial markets overreact to the interest rate projections or do not understand their conditionality.

Assessing the effect of forward guidance often suffers from the presence of confounding factors. So it is useful to consider cases in which there was a sudden communications change without any adjustment or surprise in policy settings. For instance, on 28 January 2004 the Federal Reserve modified its qualitative forward guidance from maintaining policy accommodation "for a considerable period" to being "patient" in removing it. This change of phrase seemed to have a strong effect on market sentiments, with US Treasury yields ranging from one to ten years rising by over 10 basis points (Swanson and Williams 2013), illustrating that qualitative forward guidance can be a potent tool.

Another interesting example is the switch by the Federal Reserve from its qualitative 'extended period' guidance to its quantitative, date-based 'mid-2013' guidance on 9 August 2011. This appeared to have a powerful effect on private sector expectations, increasing the expected duration of a very low policy rate from four quarters to at least seven quarters (according to the Blue Chip survey of forecasters), and reducing the two-year US Treasury yield by about 10 basis points and the five- and ten-year yields by over 20 basis points (Swanson and Williams 2013). ${ }^{28}$ This suggests that forward guidance can be much more effective when it is quantified.

\footnotetext{
${ }^{28}$ Swanson and Williams (2013) also find that the probability of very low rates derived from interest rate options rose substantially. In addition, they show that the sensitivity of one-year and two-year US Treasury yields to macroeconomic news dropped to around zero, with similar results for eurodollar futures.
} 
Unconventional monetary policy measures such as 'quantitative easing' are typically announced in advance. ${ }^{29}$ Gagnon, Raskin, Remache and Sack (2011) found large declines in longer-term interest rates on the days the Federal Reserve made announcements about large-scale asset purchase programs during the 20082009 financial crisis. They showed that the decrease in ten-year US Treasury yields could mostly be attributed to a drop in the term premium rather than lower market expectations of future policy rates. Joyce, Lasaosa, Stevens and Tong (2011) similarly found that announcements by the Bank of England regarding quantitative easing starting early 2009 were followed by substantial declines in medium- to long-term UK government bond yields that were mostly due to lower term premia. In both cases, announcing the measures made them effective even before any assets had been purchased. Furthermore, the European Central Bank announced on 6 September 2012 its 'outright monetary transactions' program of potentially unlimited sterilized purchases of euro area sovereign debt to reduce risk premia stemming from fears of a break-up of the eurozone. The announcement has proved so successful at reducing yields that the ECB has not needed to make any purchases under this program to date (late 2013). This illustrates the power of central bank communications.

To summarize, guidance about the future policy path is important to achieve transparency of monetary policy. Time-dependent policy guidance allows central banks to directly shape interest rate expectations, while state-contingent guidance offers greater flexibility to respond to changing economic circumstances. Forward guidance generally reduces uncertainty and allows the private sector to align its interest rate and inflation expectations with the central bank's intentions, making monetary policy more effective. The lower uncertainty could reduce risk premia, stimulating investment and growth. It also facilitates the implementation of optimal monetary policy in the New Keynesian model.

Forward guidance essentially gives the central bank an additional monetary policy tool to manage expectations, so it is not surprising that it has become more popular since the financial crisis in 2008-2009. With policy rates close to zero, central bank communications still provide a powerful monetary policy instrument.

\footnotetext{
${ }^{29}$ In contrast, central banks are often secretive about foreign exchange interventions, although exchange rate communications ('oral interventions') appear effective (Fratzscher 2008).
} 


\section{Conclusion}

This paper has provided a survey of monetary policy transparency. It has shown that central banks throughout the world are increasingly disclosing information relevant to their monetary policymaking. The greater openness has been strongest for macroeconomic prospects and developments and for policy announcements and explanations.

The disclosure of information generally has the effect that it reduces private sector uncertainty and makes monetary policy more predictable.

In addition, transparency about macroeconomic prospects, most prominently through the publication of macroeconomic projections, allows the public to infer the central bank's inflationary intentions from its monetary policy actions and outcomes. This imposes discipline on the central bank, while it also yields greater flexibility to pursue macroeconomic stabilization.

Furthermore, the current frontier in monetary policy transparency, forward guidance about policy settings, including the release of the projected policy path, allows the central bank to influence private sector expectations and have greater control over longer term interest rates.

In general, central bank communications constitute an additional monetary policy tool that could be utilized to align private sector expectations of inflation and interest rates with the central bank's intentions. Thus, transparency provides a policy instrument to manage expectations and thereby improve the effectiveness of monetary policy.

Empirical evidence suggests that greater transparency of monetary policy has indeed made long-term inflation expectations better anchored and monetary policy decisions more predictable, while it has also improved macroeconomic outcomes. All in all, monetary policy transparency largely appears to have been beneficial. 


\section{References}

Apel, M. and Grimaldi, M. B. (2012), 'The information content of central bank minutes', Sveriges Riksbank Working Paper 261.

Begg, I. (2006), Economic policy and institutional transparency: The ECB, in L. Oxelheim, ed., 'Corporate and Institutional Transparency for Economic Growth in Europe', Elsevier, chapter 2, pp. 47-69.

Bernanke, B. S., Reinhart, V. R. and Sack, B. P. (2004), 'Monetary policy alternatives at the zero bound: An empirical assessment', Brookings Papers on Economic Activity 2, 1-78.

Bjørnland, H. C., Ekeli, T., Geraats, P. M. and Leitemo, K. (2004), 'Norges Bank Watch 2004: An independent review of monetary policymaking in Norway', Norges Bank Watch Report 5, Centre for Monetary Economics.

Blinder, A. S. (2000), 'Central-bank credibility: Why do we care? How do we build it?', American Economic Review 90(5), 1421-1431.

Blinder, A. S., Ehrmann, M., Fratzscher, M., De Haan, J. and Jansen, D.-J. (2008), 'Central bank communication and monetary policy: A survey of theory and evidence', Journal of Economic Literature 46(4), 910-945.

Brand, C., Buncic, D. and Turunen, J. (2010), 'The impact of ECB monetary policy decisions and communication on the yield curve', Journal of the European Economic Association 8(6), 1266-1298.

Campbell, J. R., Evans, C. L., Fisher, J. D. M. and Justiniano, A. (2012), 'Macroeconomic effects of Federal Reserve forward guidance', Brookings Papers on Economic Activity 2012, 1-54.

Carpenter, S. B. (2004), 'Transparency and monetary policy: What does the academic literature tell policymakers?', Federal Reserve Board Finance and Economics Discussion Series 2004-35.

Chortareas, G., Stasavage, D. and Sterne, G. (2002), 'Does it pay to be transparent? International evidence from central bank forecasts', Federal Reserve Bank of St. Louis Review 84(4), 99-117. 
Chortareas, G., Stasavage, D. and Sterne, G. (2003), 'Does monetary policy transparency reduce disinflation costs?', The Manchester School 71(5), 521-540.

Crowe, C. and Meade, E. E. (2008), 'Central bank independence and transparency: Evolution and effectiveness', European Journal of Political Economy 24(4), 763-777.

Cukierman, A. (2001), Accountability, credibility, transparency and stabilization policy in the eurosystem, in C. Wyplosz, ed., 'The Impact of EMU on Europe and the Developing Countries', Oxford University Press, chapter 3, pp. 4075 .

Dincer, N. N. and Eichengreen, B. (2013), 'Central bank transparency and independence: Updates and new measures', International Journal of Central Banking (forthcoming).

Ehrmann, M. and Fratzscher, M. (2007a), 'Communication and decision-making by central bank committees: Different strategies, same effectiveness?', Journal of Money, Credit and Banking 39(2-3), 509-541.

Ehrmann, M. and Fratzscher, M. (2007b), 'The timing of central bank communication', European Journal of Political Economy 23(1), 124-145.

Ehrmann, M. and Fratzscher, M. (2007c), 'Transparency, disclosure, and the Federal Reserve', International Journal of Central Banking 3(1), 179-225.

Ehrmann, M. and Fratzscher, M. (2009), 'Explaining monetary policy in press conferences', International Journal of Central Banking 5(2), 41-84.

Eijffinger, S. C. and Geraats, P. M. (2006), 'How transparent are central banks?', European Journal of Political Economy 22(1), 1-21.

Faust, J. and Svensson, L. E. (2001), 'Transparency and credibility: Monetary policy with unobservable goals', International Economic Review 42(2), 369397.

Fracasso, A., Genberg, H. and Wyplosz, C. (2003), How Do Central Banks Write? An Evaluation of Inflation Targeting Central Banks, Vol. Special Report 2 of 
Geneva Reports on the World Economy, Centre for Economic Policy Research.

Fratzscher, M. (2008), 'Oral interventions versus actual interventions in FX markets an event-study approach', The Economic Journal 118(530), 10791106.

Fry, M., Julius, D., Mahadeva, L., Roger, S. and Sterne, G. (2000), Key issues in the choice of monetary policy framework, in L. Mahadeva and G. Sterne, eds, 'Monetary Policy Frameworks in a Global Context', Routledge, London, pp. 1-216.

Gagnon, J., Raskin, M., Remache, J. and Sack, B. (2011), 'The financial market effects of the Federal Reserve's large-scale asset purchases', International Journal of Central Banking 7, 3-43.

Galí, J. (2008), Monetary Policy, Inflation, and the Business Cycle: An Introduction to the New Keynesian Framework, Princeton University Press.

Geraats, P., Giavazzi, F. and Wyplosz, C. (2008), 'Transparency and governance', Monitoring the European Central Bank 6, Centre for Economic Policy Research.

Geraats, P. M. (2000), 'Why adopt transparency? The publication of central bank forecasts', CEPR Discussion Paper 2582.

Geraats, P. M. (2001), 'Precommitment, transparency and monetary policy', Bundesbank Discussion Paper 12/01.

Geraats, P. M. (2002), 'Central bank transparency', Economic Journal 112(483), F532-F565.

Geraats, P. M. (2005), 'Transparency and reputation: The publication of central bank forecasts', Topics in Macroeconomics 5(1.1), 1-26.

Geraats, P. M. (2006), 'Transparency of monetary policy: Theory and practice', CESifo Economic Studies 52(1), 111-152. 
Geraats, P. M. (2007a), 'The mystique of central bank speak', International Journal of Central Banking 3(1), 37-80.

Geraats, P. M. (2007b), 'Political pressures and monetary mystique', CESifo Working Paper 1999.

Geraats, P. M. (2009), 'Trends in monetary policy transparency', International Finance 12(2), 235-268.

Geraats, P. M. (2013), Transparency, flexibility, and macroeconomic stabilization, in P. L. Siklos and J.-E. Sturm, eds, 'Central Bank Communication, Decision Making, and Governance: Issues, Challenges, and Case Studies', MIT Press, chapter 3, pp. 49-81.

Geraats, P. M., Eijffinger, S. C. and Van Der Cruijsen, C. A. (2006), 'Does central bank transparency reduce interest rates?', CEPR Discussion Paper 5526.

Gerlach-Kristen, P. (2004), 'Is the MPC's voting record informative about future UK monetary policy?', Scandinavian Journal of Economics 106(2), 299313.

Gersbach, H. (2003), 'On the negative social value of central banks' knowledge transparency', Economics of Governance 4(2), 91-102.

Gersbach, H. and Hahn, V. (2004), 'Voting transparency, conflicting interests, and the appointment of central bankers', Economics and Politics 16(3), 321-345.

Gersbach, H. and Hahn, V. (2011), 'Monetary policy inclinations', Journal of Money, Credit and Banking 43(8), 1707-1717.

Gosselin, P., Lotz, A. and Wyplosz, C. (2008), 'The expected interest rate path: Alignment of expectations vs. creative opacity', International Journal of Central Banking 4(3), 145-185.

Gürkaynak, R. S., Levin, A. and Swanson, E. (2010), 'Does inflation targeting anchor long-run inflation expectations? Evidence from the U.S., UK, and Sweden', Journal of the European Economic Association 8(6), 1208-1242. 
Gürkaynak, R. S., Sack, B. and Swanson, E. T. (2005), 'Do actions speak louder than words? The response of asset prices to monetary policy actions and statements', International Journal of Central Banking 1(1), 55-93.

Guthrie, G. and Wright, J. (2000), 'Open mouth operations', Journal of Monetary Economics 46(2), 489-516.

Hahn, V. (2002), 'Transparency in monetary policy: A survey', ifo Studien 28(3), 429-255.

Horváth, R., Šmídková, K. and Zápal, J. (2012), 'Central banks' voting records and future policy', International Journal of Central Banking 8(4), 1-19.

Jensen, H. (2002), 'Optimal degrees of transparency in monetary policymaking', Scandinavian Journal of Economics 104(3), 399-422.

Joyce, M. A. S., Lasaosa, A., Stevens, I. and Tong, M. (2011), 'The financial market impact of quantitative easing in the United Kingdom', International Journal of Central Banking 7(3), 113-161.

Kool, C., Middeldorp, M. and Rosenkranz, S. (2011), 'Central bank transparency and the crowding out of private information in financial markets', Journal of Money, Credit and Banking 43(4), 765-774.

Moessner, R. and Nelson, W. R. (2008), 'Central bank policy rate guidance and financial market functioning', Central Bank Policy Rate Guidance and Financial Market Functioning 4(4), 193-226.

Morris, S. and Shin, H. S. (2002), 'Social value of public information', American Economic Review 92(5), 1521-1534.

Morris, S. and Shin, H. S. (2005), 'Central bank transparency and the signal value of prices', Brookings Papers on Economic Activity 2005(2), 1-43.

Reeves, R. and Sawicki, M. (2007), 'Do financial markets react to Bank of England communication?', European Journal of Political Economy 23(1), 207227. 
Rosa, C. (2013), 'The financial market effect of FOMC minutes', Federal Reserve Bank of New York Economic Policy Review 19(2), 67-81.

Rudebusch, G. D. and Williams, J. C. (2008), Revealing the secrets of the temple: The value of publishing central bank interest rate projections, in J. Y. Campbell, ed., 'Asset Prices and Monetary Policy', National Bureau of Economic Research, University of Chicago Press, pp. 247-284.

Svensson, L. E. (1997), 'Inflation forecast targeting: Implementing and monitoring inflation targets', European Economic Review 41(6), 1111-1146.

Swanson, E. T. (2006), 'Have increases in federal reserve transparency improved private sector interest rate forecasts?', Journal of Money, Credit, and Banking 38(3), 791-819.

Swanson, E. T. and Williams, J. C. (2013), 'Measuring the effect of the zero lower bound on medium- and longer-term interest rates', Federal Reserve Bank of San Francisco Working Paper 2012-02.

Tong, H. (2007), 'Disclosure standards and market efficiency: Evidence from analysts' forecasts', Journal of International Economics 72(1), 222-241.

Van Der Cruijsen, C. and Demertzis, M. (2007), 'The impact of central bank transparency on inflation expectations', European Journal of Political Economy 23(1), 51-66.

Van Der Cruijsen, C. and Eijffinger, S. C. W. (2010), The economic impact of central bank transparency: A survey, in P. L. Siklos, M. T. Bohl and M. E. Wohar, eds, 'Challenges in Central Banking: The Current Institutional Environment and Forces Affecting Monetary Policy', Cambridge University Press, chapter 9, pp. 261-319.

Van Der Cruijsen, C., Jansen, D.-J. and De Haan, J. (2010), 'How much does the public know about the ECB's monetary policy? Evidence from a survey of dutch households', ECB Working Paper 1265.

Walsh, C. E. (2007), 'Optimal economic transparency', International Journal of Central Banking 3(1), 5-36. 
Weber, A. (2010), 'Communication, decision making, and the optimal degree of transparency of monetary policy committees', International Journal of Central Banking 6(3), 1-49.

Winkler, B. (2002), 'Which kind of transparency? On the need for effective communication in monetary policy-making', ifo Studien 48(3), 401-427.

Woodford, M. (2005), Central bank communication and policy effectiveness, in 'The Greenspan Era: Lessons for the Future', Federal Reserve Bank of Kansas City Economic Symposium, Federal Reserve Bank of Kansas City, pp. 399-474.

Woodford, M. (2012), Methods of policy accommodation at the interest-rate lower bound, in 'The Changing Policy Landscape', Economic Symposium Conference Proceedings, Federal Reserve Bank of Kansas City, pp. 185-288. 